\title{
Las ligas femeninas ante el alcoholismo y la salubridad en el México posrevolucionario, 1934-1946*
}

\author{
Women's Leagues facing Alcoholism and Salubrity \\ in Post-Revolutionary Mexico, 1934-1946
}

\author{
Manuel Ramírez Chicharro \\ ORCID iD: https://orcid.org/0000-0002-3347-1285 \\ Instituto de Investigaciones Históricas, \\ Universidad Nacional Autónoma de México, México
}

El objetivo de este artículo es analizar cómo las ligas femeninas de distintos Estados de la República de México se dotaron de entidad jurídica y se constituyeron en sujeto político reivindicativo que, junto a la lucha por los derechos de las mujeres, reivindicó otro tipo de mejoras materiales como reducir las altas tasas de alcoholismo y mejorar las condiciones de salubridad en sus localidades. Concretamente se estudiarán aquellos grupos y asambleas impulsados por o vinculados al Frente Único Pro Derechos de la Mujer (19351940) y al Bloque Nacional de Mujeres Revolucionarias (1940-1946) durante los gobiernos de Lázaro Cárdenas y Manuel Ávila Camacho.

Palabras clave: México; Posrevolución; Ligas Femeninas; Feminismo; Peticiones.

The objective of this article is to analyze how women's leagues of different States of the Republic of Mexico were endowed with a legal entity and became a vindictive political subject that, coupled with the fight for women's rights, claimed other types of material developments such as reducing the high rates of alcoholism and improving the sanitation conditions in their localities. Specifically, the groups and assemblies promoted by or linked to the United Front for Women's Rights (1935-1940) and the National Bloc of Revolutionary Women (1940-1946) during the governments of Lázaro Cárdenas and Manuel Ávila Camacho will be studied.

KeYwords: Mexico; Post-revolution; Women's Leagues; Feminism; Requests.

Copyright: (C) 2021 CSIC. Este es un artículo de acceso abierto distribuido bajo los términos de la licencia de uso y distribución Creative Commons Reconocimiento 4.0 Internacional (CC BY 4.0).

* Esta investigación ha sido realizada en el Instituto de Investigaciones Históricas de la UNAM como parte del Programa de Becas Posdoctorales en la UNAM bajo la asesoría de Claudia Agostoni, así como en el marco del proyecto de investigación «El orden y sus desafíos en el Circuncaribe hispano, 1791-1960» (RTI2018-094305-B-I00PHAHIS6). 


\section{Introducción}

El objetivo de este artículo es analizar la implicación de las ligas femeninas en la lucha contra el alcoholismo y la mejora de las condiciones de salubridad durante los gobiernos de Lázaro Cárdenas y Manuel Ávila Camacho. Se estudiará cómo mujeres de distintos estados de México se dotaron de entidad jurídica y se constituyeron en sujeto político reivindicativo a través de ligas impulsadas por o vinculadas al «Frente Único Pro Derechos de la Mujer en México»(FUPDM) y, desde 1940, al «Bloque Nacional de Mujeres Revolucionarias»(BNMR). Las ligas, en tanto entidades colectivas, ayudaron a legitimar y convertir sus particulares visiones sobre la cuestión y la justicia social en un programa político de transformación que se alineaba, y en ocasiones dotaba de nuevas perspectivas, al proyecto revolucionario. Al agruparse para obtener la ciudadanía, las mujeres también incorporaron al debate otras experiencias agregadas. Estos nuevos espacios abrieron la oportunidad de debatir y generar teoría a partir de las carencias compartidas. Desde cuestiones de representación política como el voto a necesidades materiales como la carencia de servicios básicos, las feministas fueron definiendo demandas y acciones que extralimitaban, y por tanto resignificaban, la agenda feminista nacional y el mismo programa revolucionario mexicano.

Para obtener una visión panorámica del fenómeno, esta investigación ha utilizado las peticiones que las ligas regionales femeninas vinculadas al FUPDM o al BNMR enviaron al despacho presidencial entre 1934 y 1946. Esta documentación se conserva en los fondos presidenciales de Lázaro Cárdenas y Manuel Ávila Camacho del Archivo General de la Nación en Ciudad de México. Por lo general, las misivas e informes eran remitidos por la secretaria de la liga al despacho presidencial de la República, el cual, a su vez, bien las resolvía, bien las derivaba a las secretarías competentes. Por lo general, los expedientes conservan la documentación generada desde la apertura del caso hasta la resolución del procedimiento. En ocasiones se desconoce qué solución se ofreció a los problemas o ruegos de las ligas, ya sea por silencio administrativo, ya porque la documentación no se archivó en las carpetas consultadas. Solo en casos excepcionales puede constatarse que las misivas de las ligas que llegaron a instancias federales fueron previamente evaluadas por autoridades estatales. Cuando esto sucede, suele explicarse por qué se ha elevado el documento petitorio a una instancia superior, lo que normalmente estaba relacionado con la extralimitación de 
competencias que acusaban los Estados en materia de fomento, educación o sanidad, pero también por el escaso compromiso con la ciudadanía, la excesiva burocracia y la ausencia de interés por gestionar problemas sociales.

Para el análisis de fuentes, se han desglosado las peticiones formuladas por las ligas según fuesen encaminadas a enfrentar el alcoholismo o a potenciar las políticas de salubridad e higienismo. Ambas cuestiones aparecen habitualmente imbricadas con reivindicaciones explícitas a los derechos y libertades de las mujeres. De modo que los diagnósticos de las ligas femeninas sobre estas problemáticas incorporaron los proyectos socializantes de Lázaro Cárdenas y conservador de Manuel Ávila Camacho relativos a la modernización de los hábitos, la moral y el bienestar social, pero también puntos clave de los programas emancipadores para las mujeres del FUPDM y del BNMR.

Este trabajo parte de los aportes realizados por historiadoras como María Teresa Fernández Aceves, Esperanza Tuñón, Enriqueta Tunón, Gabriela Cano, Jocelyn Olcott, Verónica Oikión o Mary Kay Vaughan. Desde diferentes posturas interpretativas respecto al feminismo en esta época, estas autoras coinciden en al menos dos cuestiones básicas. Primero, que las libertades y la movilidad feminista fueron más amplias, dinámicas, radicales y propositivas en el periodo cardenista debido a los intereses comunes y proyectos negociados entre el gobierno y el FUPDM. Y, segundo, que la no aprobación del voto por Cárdenas en 1939 y la implantación del proyecto conservador de Unidad Nacional por Ávila Camacho frenaron las aspiraciones emancipadoras de las mujeres y reimplantaron los estereotipos tradicionales sobre el rol social de las mujeres en el marco de la familia y el Estado. De tal modo que, según estas interpretaciones, el feminismo habría perdido capacidad de presión y de negociación debido al fracaso en obtener el sufragio femenino y por las trabas que los cambios ideológicos y programáticos derivados de la sucesión gubernamental tuvieron sobre la emancipación de las mujeres. ${ }^{1}$

Sin deslegitimar estos argumentos plenamente constatados por la literatura existente, este artículo pretende matizar sus conclusiones. Es cierto que el BNMR, la federación que trató de canalizar el impulso generado por el FUPDM en la década anterior, nunca alcanzó a tener la resonancia de su predecesora en la lucha por el voto. Ahora bien, la documentación

1 Tuñón Pablos, 1992. Tuñón, 2011. Fowler-Salamini y Mary Kay, 2003. Olcott, 2007. Cano, Vaughan y Olcott, 2009. Fernández Aceves, 2014. Oikión Solano, 2018. Sobre las peticiones de mujeres, para el caso argentino, véase el reciente trabajo de Paz Trueba y Bracamonte, 2020. 
analizada en este artículo sugiere que, a pesar del contragolpe sufrido por las feministas en los años cuarenta, el BNMR tuvo la capacidad de mantener activas y dar apoyo a las ligas femeninas fundadas por el movimiento en la década anterior y ofrecer cobertura a los nuevos grupos que surgieron durante los años cuarenta. ${ }^{2}$ Este punto resulta especialmente relevante por dos motivos. Por un lado, para entender que las ligas femeninas fueron impulsadas - pero también se asumieron oficiosamente- como un eslabón más de la maquinaria corporativa federal. Esto sucedió desde la misma fundación del Partido Nacional Revolucionario (PNR) por Plutarco Elías Calle en 1929, el cual buscaba articular de forma controlada a la sociedad civil mediante organizaciones de masas obrera, campesina y popular, un proceso que se aceleró cuando en 1938 Cárdenas fundó el Partido de la Revolución Mexicana (PRM). Por otro, para comprender que, ya fuera bajo un régimen nacionalista con rasgos socializantes - como sugiere la historiografía revisionista - o bajo uno nacionalista y conservador, las ligas supieron adaptarse al lenguaje del poder para dotar a las mujeres de cierta entidad jurídica frente a las instancias federales en un contexto en el que aún no había sido aprobado el voto femenino a nivel local ni nacional.

En este estudio se plantea como hipótesis que considerar los años cuarenta como un periodo de inacción feminista en México es una valoración que se sostiene exclusivamente si asumimos que solo la lucha por el voto dio razón de ser al movimiento feminista. Es decir, si evaluamos el éxito del feminismo en función de los derechos políticos obtenidos por las feministas y si consideramos que la lucha por el voto siempre fue la demanda más importante para absolutamente todas las mujeres. Ambas ideas descartan implícitamente que otras peticiones de carácter socio-económico planteadas por mujeres de estas ligas tuvieran relación con la lucha feminista. Esos puntos de partida también olvidan que para una gran mayoría de ellas quizás resultaba menos urgente y liberador conseguir la ciudadanía plena que exigir reformas para aliviar su carga laboral dentro y fuera del hogar, y con

2 Son numerosos los ejemplos en ambos casos. Véase el apoyo del FUPDM a la Liga Femenina Pro Derechos de la Mujer de Oaxaca mediando con Lázaro Cárdenas frente a empresas de Tehuantepec que las explotaban a sus trabajadoras, octubre de 1939, Archivo General de la Nación de México, Ciudad de México (AGN), Secretaría de Gobernación, Presidentes, Lázaro Cárdenas (LC), 152, exp. 151.3/879. Respecto al BNMR, véase el apoyo provisto a la Liga Femenil Eufrosina Camacho Viuda de Ávila en Ixtacalc, 26 de agosto de 1946, AGN, Secretaría de Gobernación, Presidentes, Manuel Ávila Camacho (MAC), 513, exp. 462.1/15; a la Federación de Organizaciones Femeninas de Yucatán, octubre de 1945, AGN, MAC, 513, exp. 462.1/15; o el respaldo a 189 grupos integrantes de la Federación de Organizaciones Femeniles del Estado de Sinaloa o 280 asambleas de la Federación de Ligas Femeninas de la Comarca Lagunera, ambos casos en septiembre de 1945, AGN, MAC, 900, exp. 562.4/24. 
las que de paso pudieran beneficiar también a sus familiares y convecinos. En este sentido, cabe anticipar que el BNMR no defendió como principal premisa la reforma electoral que permitiera a las mujeres elegir o ser electas. Por el contrario, la sección femenina del Partido Comunista de México (PCM) buscó facilitar la entrada de las mujeres al sistema educativo, adquirir conocimientos técnicos para optar a empleos remunerados, y mejorar su bienestar y solventar sus carencias materiales, lo que indirectamente también podría contribuir a mejorar el nivel de vida de sus convivientes y en su comunidad.

Para esta investigación resulta pertinente recordar que, aunque el «feminismo» no aparece en México como idea política así expresada hasta comienzos del siglo XX, el concepto amplio que engloba la necesidad de que las mujeres ganasen mayores derechos y libertades, como el acceso a la educación básica y técnica en igualdad, o a un trabajo remunerado, fue utilizado ya en la prensa «para mujeres» como Las hijas del Anahuac (1873), El álbum de la mujer (1883-1890) y, sobre todo, La Mujer Mexicana (19041907). ${ }^{3}$ Poco después, en plena revolución, palabras como «feminismo» y «feminista» ya fueron mencionadas en esos mismos términos por Hermila Galindo en los discursos que ofreció durante los congresos feministas de Yucatán, organizados a instancias de los gobernadores Carrillo Puerto y Salvador Alvarado Rubio. ${ }^{4}$ Por tanto, a la hora de utilizar en este artículo los términos «feminismo» $\mathrm{o}$ «feministas» para aludir a las demandas, propuestas y a acciones de las ligas femeninas, se está remitiendo a una terminología política contextualizada que se utilizaba en el periodo analizado, si bien es cierto que convivieron posturas feministas divergentes y a veces contrapuestas (socialista, radical, liberal y conservadora) ${ }^{5}$

Ahora bien, como se analizará en las próximas páginas, las ligas del FUPDM y el BNMR estuvieron tan comprometidas con la lucha contra el alcoholismo o con mejorar la salubridad en sus lugares de origen como con los derechos políticos de las mujeres. La escasa preocupación mostrada por las ligas femeninas vinculadas al BNMR hacia la cuestión del voto no cancela su naturaleza feminista, sino que la complejiza y enriquece. Al fin y al cabo, sus ruegos petitorios respecto al alcoholismo y la salubridad contemplan simultáneamente mejoras para las mujeres o, cuanto menos,

3 Hernández Carballido, 2012, 64-81.

4 Peniche Rivero, 2017, 23-48. Tuñón Pablos y Martínez Ortega, 2017, 1-35.

5 Lau Jaiven y Rodríguez Bravo, 2017, 57-81. Para el llamado «feminismo católico», véase Espinoza Meléndez, 2020. 
interpretan los problemas sociales y materiales que les afectaban desde un punto de vista claramente marcado por su experiencia como mujeres dentro de sus comunidades. Por ello, el hecho de que organizaciones autodefinidas tan solo como «femeninas» tuvieran premisas, programas, peticiones y actuaciones que de facto permitan definirlas como «feministas», obliga a revisar las fronteras conceptuales entre «feminismo» $\mathrm{y}$ «activismo social».

A esta discusión hay que añadir otra consideración. Las feministas mexicanas, puntualmente las nacionalistas del PNR, pero sobre todo las socialistas revolucionarias vinculadas al PCM, entendieron la emancipación femenina y la justicia social como aspectos inexorablemente unidos. Es decir, la liberación de las mujeres no podía conseguirse garantizando tan solo los derechos políticos que demandaban, sino también impulsando cambios en las regulaciones civiles, sociales y, sobre todo, económicas. Debe subrayarse al respecto que entre las filas del FUPDM y el BNMR predominaron mujeres socialistas para las cuales la categoría «clase» tuvo una importante relevancia frente a otras aún inexistentes, pero tácitamente presentes, como «género» $\mathrm{y}$ «relaciones de género». Es cierto que ninguna de las organizaciones planteaba abiertamente romper con los estereotipos de género vigentes en la época. Sin embargo, el mero hecho de que estuvieran demandando reformas tocantes a elementos estructurales como el modelo educativo o productivo para facilitar la emancipación de las mujeres, constata un interés por renegociar los códigos morales que tradicionalmente habían regulado y fundamentado el «deber-ser-mujer» en sociedad, y por tanto su exclusión de la educación técnica y el empleo regulado. ${ }^{6}$

De igual modo, este artículo quiere entablar un diálogo con la historiografía que problematiza las cronologías de la revolución y la posrevolución. Independientemente de si la Revolución Mexicana tuvo un carácter burgués, socialista-centrista o proletario-marxista, existe determinado consenso al afirmar que finalizó en algún momento entre 1917 y 1924, mientras la posrevolución terminó entre 1938 y 1940, si bien autores como Adolfo Gilly retrasan su conclusión hasta $1971 .{ }^{7}$ Esto resulta válido para cuestiones institucionales concernientes al cambio en la estructura estatal, el mayor control federal de la economía, las reformas agrarias, la relación entre partidos y ciudadanía masculina, o las organizaciones de masas esenciales en la articulación de un proyecto rupturista respecto al pasado caudillista legado por Porfirio Díaz. Desde la historiografía feminista, sin embargo, estas

6 Santillán, 2010, 91-110.

7 Knight, 1986, 5-32. Anaya Merchant, 1995, 525-536. Basurto, 2019, 23-48. 
periodizaciones merecerían ser revisadas. Al fin y al cabo, las promesas sufragistas enunciadas en los congresos feministas de Yucatán y debatidas en la asamblea constituyente de Querétaro que redactó la Constitución de 1917, no fueron aprobadas hasta 1953 y no entraron en funcionamiento hasta los comicios de 1955. Por ello, si el concepto «posrevolución» aspira a englobar el periodo en el que la revolución se hizo institución y en el que su legado ideológico pasó a tomar cuerpo de ley, este artículo vendría a cuestionar que su final se establezca en torno a 1940, proponiendo como alternativa extenderlo, al menos, hasta $1955 .^{8}$

Como se verá a continuación, tanto las ligas vinculadas al FUPDM como al BNMR incorporaron a sus programas y demandas feministas elementos sociales, laborales, económicos y de salubridad que atañían tanto a las mujeres como a la sociedad en su conjunto. Este solapamiento ideológico y programático debe entenderse en una coyuntura de especial complejidad. En los años treinta y cuarenta, la autonomía de las agrupaciones de masas estaba cada vez más supeditada a la expansión y consolidación del Estado posrevolucionario de carácter corporativista. Las ligas femeninas se vieron en la obligación de — pero también tuvieron la habilidad paraasumir diversos lenguajes políticos para conseguir los objetivos que perseguían. En general, mostraron gran flexibilidad de adaptación a los distintos códigos e ideologías que operaron durante la revolución cardenista y la contrarrevolución camachista para obtener réditos específicos. Estas ligas y asociaciones no solo velaron por ampliar los derechos de las mujeres, sino que actuaron como centinelas del proyecto revolucionario a pequeña escala. Ante las promesas incompletas o incumplidas por las distintas entidades administrativas, las ligas mostraron una actitud negociadora pero firme que recordaba y alertaba sobre la necesidad y la obligación de materializarlos. Y en esta superposición de intereses y necesidades, de hegemonías y contrapoderes, el feminismo y la justicia social aparecieron habitualmente solapados.

8 Esta fecha es una mera sugerencia tentativa ya que su aceptación podría recaer en el mismo sesgo historiográfico que anteriormente se criticaba: dar preponderancia a la aprobación del sufragio sobre el resto de demandas y actuaciones feministas. Con el mismo argumento, la historiografía sobre los pueblos originarios podría cuestionar que el periodo posrevolucionario finalizase con la consideración de las mujeres como ciudadanas o con la obtención de mayores derechos sexuales desde los años ochenta. Como alternativa, los pueblos originarios quizás podrían plantear la necesidad de extender esta cronología de la posrevolución hasta, quizás, los acuerdos de San Andrés en 1996, o proponer incluso, con razón, que ese ciclo aún no ha terminado. El debate adquiere así una dimensión historiográfica y ontológica ¿qué fue la revolución? ¿qué es y hasta dónde es posible extender el término «posrevolución»? 


\section{EI FUPDM, el BNMR y la constitución de las Ligas Femeninas}

La Constitución mexicana de 1917 no ratificó el sufragio universal femenino, a pesar de que en 1916 se habían convocado dos congresos femeninos en Yucatán en los que se había solicitado abiertamente esta reforma. Hasta 1940, seis Estados concedieron el derecho al sufragio: Yucatán, 1922; San Luis Potosí, 1923 (que lo revocó en 1926); Chiapas 1925; Tabasco, 1934 (que también lo revocó), Puebla y Michoacán en 1939. ${ }^{9}$

En este periodo, se constituyó el FUPDM (1934) para responder y respaldar a las demandas de las mujeres. Entre sus integrantes fundacionales se encontraban mujeres comunistas, penerretistas y católicas provenientes de veinticinco organizaciones diferentes. Un año después, el FUPDM creó el Consejo Nacional del Sufragio Femenino, el cual organizó el primer Congreso Nacional de Mujeres y presionó a las instituciones federales para aprobar el sufragio femenino. Según estiman Verónica Oikión y Esperanza Tuñón, el FUPDM llegó a contar con un núcleo de 50.000 mujeres afiliadas a través de ochocientas organizaciones. ${ }^{10}$ Algunas de sus líderes más destacadas fueron Refugio García (Cuca), Esther Chapa y Adelina Zendejas. El surgimiento del FUPDM respondió no solo a la movilización de las organizaciones feministas, y en especial a la movilización de las comunistas, sino también a las directrices estratégicas aprobadas en el VII Congreso de la Tercera Internacional Comunista, en el cual se delineó la creación de los frentes populares contra el fascismo emergente tras el crack de 1929.

El FUPDM, sin embargo, no consiguió que el sufragio femenino se aprobase bajo la legislatura de Cárdenas. A pesar de que solicitó una enmienda constitucional en 1937, la cual fue apoyada por veintiocho Estados, el creciente poder de los sectores moderados al interior del PRM, la presunción de que la aparente religiosidad de las mujeres favorecería los intereses los conservadores ${ }^{11}$ y la cercanía de los comicios de 1940, terminaron por paralizar la ratificación de la medida. Después, durante la legislatura de Miguel Alemán, se aprobó la reforma del sufragio femenino en comicios municipales (1946) y, bajo Adolfo Ruiz Cortines, el sufragio

9 De la Torre Torres y Olalde Vázquez, 2018.

10 Tuñón Pablos, 1992, 67-68 y 93. Oikión Solano, 2018, 256.

11 Las guerras cristeras y el sinarquismo tuvieron un gran impacto en la génesis de un feminismo de corte conservador, católico y nacionalista en México, elementos no siempre coincidentes. Respecto al primer punto, véase Vaca, 1998; Álvarez-Pimentel, 2017. Respecto al segundo, Rodríguez Bravo, 2013; Orozco-García, 2019. 
para las mujeres en elecciones nacionales (1953). ${ }^{12} \mathrm{El}$ desgaste padecido por el FUPDM durante la campaña a favor del sufragio y su fracaso en la materialización de la reforma electoral llevó a que su líder, Refugio García, abandonase la dirección de la organización, lo que poco después llevó a su disolución. ${ }^{13}$ Como explica Selene de Dios Vallejo, esta coyuntura conllevó la atomización del movimiento feminista. En los años siguientes, solo la Alianza de Mujeres, de Amalia Castillo Ledón, o el BNMR, del que se ocupa este artículo, intentaron contener la dispersión del impulso feminista bajo el gobierno de Manuel Ávila Camacho. ${ }^{14}$

El BNMR se fundó en 1941 y fue sustituido por la Unión Democrática de Mujeres en 1951. Ambas fueron impulsadas y operaron como secciones femeninas del PCM. En cierto sentido, el BNMR se vio limitado y debilitado por la desaparición de la III Internacional en 1943 y la crisis interna del propio PCM en esos mismos años. Sin embargo, podría igualmente sugerirse que la organización reflotó cuando en 1945 se constituyó en sección mexicana de la Federación Democrática Internacional de Mujeres, entidad internacional fundada en París por ochocientas mujeres antifascistas vinculadas al Partido Comunista de la Unión Soviética y a los respectivos partidos comunistas de sus países. ${ }^{15}$

Existían importantes diferencias estructurales e ideológicas entre el FUPDM y el BNMR. El primero fue una organización interpartidista e interclasista cuyas integrantes tenían signos ideológicos diversos, aunque el liderazgo corrió a cargo de las comunistas. El segundo operó exclusivamente como organización femenil del PCM. A pesar de sus disimilitudes, hay que destacar que existió continuidad entre las integrantes comunistas

12 Sobre la concesión del sufragio a las mujeres en elecciones municipales véase «Decreto que adiciona el párrafo primero de la fracción primera del artículo 115 de la Constitución Política de los Estados Unidos Mexicanos», Diario Oficial. Órgano del Gobierno Constitucional de los Estados Unidos Mexicanos, Secretaría de Gobernación, 12 de febrero de 1947, 3-4. Disponible en: https://www. dof.gob.mx/index_113.php?year=1947\&month=02\&day=12 [Consultado: 14/01/2020]. Sobre la concesión del sufragio a las mujeres en elecciones nacionales véase «Decreto que reforma los artículos 34 y 115 de la Constitución Política de los Estados Unidos Mexicanos», Diario Oficial. Órgano del Gobierno Constitucional de los Estados Unidos Mexicanos, Secretaría de Gobernación, 17 de octubre de 1953, 1-2. Disponible en: https://www.dof.gob.mx/index_113.php?year=1953\&month=10\&day=17 [Consultado: 14/01/2020].

13 Oikión Solano, 2018.

14 De Dios Vallejo, 2014.

15 De Haan, 2010, 547-573. Sobre la relación entre el BNMR y la Women's International Democratic Federation (WIDF) o, en su versión española, Federación Democrática Internacional de Mujeres véase Oikión Solano, 2017, 153-173. Los demás capítulos de ese libro analizan esta misma vinculación entre la WIDF y otras mujeres comunistas de América Latina. Más información sobre la proyección de la WIDF hacia el llamado «tercer mundo» en Gradskova, 2020, 270-288. 
de ambas plataformas. Por ejemplo, la secretaria general del BNMR, Estela Jiménez Esponda, había dirigido la secretaría de educación del FUPDM; Adelina Zendejas, antes mencionada, fue fundadora del FUPDM y después secretaria de prensa del BNMR, mientras que Esther Chapa, a quien también se ha aludido, integró el FUPDM en los años treinta y después ejerció como secretaria de acción política del BNMR.${ }^{16}$ Además, tanto el FUPDM como el BNMR analizaron problemáticas sociales como el alcoholismo y la salubridad partiendo de las necesidades específicas de las mujeres, pero asumiendo también el programa del PCM concerniente a la justicia social y el mejoramiento de las condiciones materiales. Tanto es así que, según Tuñón Pablos, el programa de la FUPDM solo contenía cinco demandas encaminadas a mejorar los derechos de las mujeres. El resto, aunque vinculadas a su bienestar, abarcaban a otros grupos como el campesinado, las poblaciones indígenas o los trabajadores. Por ejemplo, planteaba la puesta en marcha de un seguro social a costa del gobierno y las empresas, la rebaja de las rentas de inmuebles, de las tarifas energéticas o de los alimentos de primera necesidad. ${ }^{17}$

Por su vinculación con el FUPDM y con el BNMR, las ligas femeninas surgidas en los ámbitos locales operaron como plataformas receptoras y divulgadoras de los programas aprobados por las matrices centrales situadas en la capital. Sin embargo, estas mismas secciones regionales confeccionaron sus propios memoriales y proclamas en sentido inverso. Sus misivas no pasaban necesariamente por la dirección de la federación a la que estaban afiliadas, sino que eran consensuadas por sus integrantes de base para después ser enviadas bien a las ligas campesinas de la región buscando su apoyo, bien a las instancias estatales y federales para solicitarles concesiones. En cierto sentido, con estos flujos de diálogo, las ligas reforzaron la hegemonía centrípeta del Estado corporativista posrevolucionario. Las ramificaciones del FUPDM y el BNMR tan solo descentralizaron parcialmente los epicentros de la gestión y de las decisiones, lo que, en cualquier caso, contribuía a extender los brazos federales hasta las municipalidades más remotas. De hecho, lejos de oponerse al control o al dominio del Estado, reconocieron a las secretarías estatales y federales como interlocutoras válidas de sus demandas, alineándose con el proyecto revolucionario cardenista o matizando las agendas del gabinete avilacamachista.

16 Cano, 1993, 387-400. Portugal Speedle, 237-249. Estudillo García; Lau Jaiven y Nieto Arizmendi, 2019, 224-225.

17 Tuñón Pablos, 1992, 63-70, citado en Cueva Tazzer, 2009, 88. 
La innovación de las ligas estriba en los planteamientos sobre las relaciones entre las mujeres, el Estado mexicano y el bienestar de la ciudadanía. Las ligas definían implícitamente un papel alternativo para las mujeres en el marco del proyecto modernizador posrevolucionario, lo que conllevaba también a cuestionar las propias concepciones de los poderes hegemónicos sobre un progreso y una modernidad que excluía o infravaloraba a la mitad de la nación. En consecuencia, estas propuestas y exigencias obligaban de alguna forma a que el Estado se replantease cómo materializar y enriquecer sus promesas de futuro hacia las mujeres y el papel de estas en la sociedad.

Las exigencias de las ligas locales raramente tuvieron que ver con derechos de representación o igualdad política de las mujeres. Sin lugar a dudas, la conceptualización de sus demandas debía mucho a la ideología y los programas del FUPDM y del BNMR divulgados por sus delegadas y representantes a lo largo del país. Sin embargo, quizás la fuente de inspiración para sus pliegos petitorios estaba en las gestiones realizadas en su vida cotidiana para solventar los problemas relativos a las carencias y necesidades materiales que por mandato de género se vieron obligadas a atender. Y dado que esos códigos y normas inculcados, asumidos y reproducidos estaban en estrecha relación con el cuidado hacia la infancia, la ancianidad y la gestión de la economía doméstica, podría decirse que sus primeras experiencias de carácter feminista buscaban aliviar las cuestiones que les afectaban negativamente a ellas mismas, pero indirectamente también a sus familias y convecinos más cercanos. En ese sentido, las demandas interpuestas por las ligas respecto al problema del alcoholismo y la insuficiencia de salubridad denotaban interpretaciones construidas desde una «epistemología feminista», o cuanto menos desde la experiencia ontológica del «ser mujer» en el México de los años treinta. ${ }^{18}$ Por ello, puede afirmarse que los memoriales escritos por las ligas, sin desligarse totalmente de la liberación de las mujeres, mostraron marcos referenciales y lugares de enunciación más diversos, complejos e inmediatos de lo que podrían parecer a primera vista.

Estas teorizaciones y acciones definidas y planteadas por individualidades aliadas en asociaciones definieron marcos interpretativos y construyeron plataformas de representación local prácticamente inexistentes en México hasta la fecha. Ante las limitaciones impuestas por el Estado corporativo posrevolucionario que todavía negaba a las mujeres los derechos asociados a la ciudadanía, las ligas contribuyeron a pluralizar y extender las plataformas

18 Hershfield, 2008. 
cívicas en las que estas podían participar y desde donde podían pronunciarse. La unión colectiva proveyó a algunas mujeres de la legitimidad y los instrumentos legales necesarios para cabildear y negociar frente a un Estado en general abierto a dialogar con las organizaciones de masas. ${ }^{19}$ Es decir, para ejercer presión y reformar las leyes existentes o para generar medidas que atendiesen aspectos previamente desconsiderados o infravalorados.

Las ligas combinaban argumentos revolucionarios y conservadores en relación al feminismo, la salubridad y la higiene social. Por un lado, sumaron a la demanda del voto impulsada por el FUPDM en la capital otras cuestiones materiales ligadas al bienestar de la comunidad. Para abordar la cuestión del alcoholismo utilizaron argumentos similares al Departamento de Salubridad, las revistas policiales o el movimiento femenino de temperancia. ${ }^{20} \mathrm{Y}$, en relación a la provisión de aguas salubres, solían ceñirse a exigir el mero cumplimiento de los programas de actuación diseñados desde las instancias competentes. Ahora bien, aunque en ambos campos aludieron a criterios sanitarios, moralizantes e incluso patrióticos compartidos por otros grupos políticos, también incorporaron demandas relativas a la integridad física y la honorabilidad de las mujeres, como se explica en los siguientes apartados.

\section{El alcoholismo: problema social y explotación femenina}

Durante el porfiriato ya se tomaron acciones contra la apertura de nuevos expendios de bebidas alcohólicas, como explica Rojas Sosa. Sin embargo, las campañas nacionales más importantes en este aspecto tuvieron lugar durante el periodo posrevolucionario y, más específicamente, desde la presidencia de Plutarco Elías Calles. En el gobierno de Emilio Portes Gil se actuó contra pulquerías, cervecerías, cantinas y cabarets por razones moralizantes, biologicistas e higienistas ligadas a determinadas concepciones del progreso y la defensa nacional, pero también sobre la construcción ideológica racializada de la nación mexicana «mestiza». ${ }^{21}$

19 Zapata Schaffeld, 2004.

20 Mitchell, 2007.

21 Vargas Reynoso (2018). «Campaña contra el alcoholismo bajo la presidencia de Emilio Portes Gil», Archivo Histórico de la Secretaría de Salubridad «Rómulo Velasco Ceballos», Ciudad de México, Fondo Secretaría de Salubridad y Asistencia, Subsecretaría de Asistencia, vol. 18, exp. 10, donde se explica la lucha contra la adicción al alcohol y el intento de suprimir el servicio de meseras en los cabarets. En este expediente también se incluye el folleto «La lucha de la mujer contra el vicio del alcohol». Sobre la construcción ideológica de la nación «mestiza» por medio de políticas y prácticas higienistas, así como de hábitos sociales y culturales véase Urias Horcasitas, 2007. 
En aquel momento, instancias estatales como el Departamento de Salubridad y medios de comunicación conservadores como Mundo Cristiano comenzaron a elaborar discursos advirtiendo de que el consumo de alcohol podía contribuir a la degeneración mental de las personas que lo consumían. Esto provocaría la perturbación de los estereotipos masculinos y femeninos normativos, la intoxicación de la «raza» y, por tanto, la obstaculización del proyecto nacional revolucionario de progreso cultural. El abuso de embriagantes llevaría a que ellos desatendiesen «sus» obligaciones como proveedores del hogar, mientras a ellas las inclinaría hacia el vicio y las zonas inmundas de la ciudad, pudiendo llegar a ser confundidas con las prostitutas registradas como tales. Por otro lado, el Magazine de la Policía constataba que hasta el $90 \%$ de las riñas registradas se habían dado en contextos de consumo excesivo de alcohol, un problema que los dispositivos culturales como el cine solían asociar con las clases sociales más desfavorecidas. ${ }^{22}$

Los discursos oficiales se posicionaron contra la instalación de nuevas pulquerías y tabernas por razones legales y productivas. Por ejemplo, en una carta remitida a la dirección general de gobernación (1945), la secretaría del Distrito Federal indicaba que «en relación con el decreto que prohíbe el establecimiento de negocios de bebidas embriagantes en las colonias proletarias», se impediría la apertura de una pulquería en Ciudad de México porque «además de causar perjuicios morales y económicos a las familias de los trabajadores, viola un Decreto que todos estamos obligados a obedecer y respetar». ${ }^{23}$

A estas cuestiones morales (pureza social y religiosa), políticas (progreso y defensa nacional), sociológicas (equilibrio familiar) e higienistas (salud de la ciudadanía), las ligas sumaron argumentos laborales, sociales y feministas definidos a partir de la praxis cotidiana desde el ser-mujer y en la relación diaria con sus círculos sociales. Sus protestas y propuestas buscaban, primero, reducir la violencia en los hogares y el abandono de las responsabilidades parentales; segundo, el absentismo escolar y la posibilidad de que niños y niñas cayeran en el alcoholismo; y, tercero, la opresión y el acoso que sufrían las meseras y trabajadoras en locales nocturnos, los cuales eran casi exclusivamente frecuentados por clientela masculina.

En este sentido, las ligas femeninas no solo se manifestaron contra la apertura de nuevos dispensarios de bebidas alcohólicas, sino que también

22 Rojas Sosa, 2019, 137-148.

23 Correspondencia entre la Liga Defensora de Inquilinos y el Departamento del Distrito Federal, México D. F., julio de 1944 a mayo de 1945, AGN, MAC, 854, exp. 553/123. 
sugirieron y elaboraron propuestas novedosas para combatir las adicciones resultantes. Dado que carecían de las herramientas para afrontar estas problemáticas por la vía legal, las mujeres plantearon estrategias preventivas en lugar de punitivas. En lugar de abundar en sanciones o medidas disciplinarias, buscaron disuadir su consumo por medio del deporte. Por ejemplo, en Tamaulipas, la Liga Femenil de Lucha Social proponía a Cárdenas que «en vista de la necesidad que se nos presenta ante la juventud de este poblado y deseando combatir el vicio del alcoholismo hemos organizado un Club deportivo para el que solicitamos un equipo de Beisbol o Bolibol [sic]».. ${ }^{24}$ Del mismo modo, la Liga Femenil del poblado Zopilotita, Culiacán (Sinaloa), solicitaba que se suspendiese la venta de insumos alcohólicos porque «no hay otra diversión y nuestros esposos, hermanos e hijos, malversan el raquítico salario que ganan en su trabajo». En un documento petitorio, reclamaron a la presidencia la financiación de instalaciones y materiales para incentivar la práctica deportiva entre niños y adolescentes, incentivándoles así un nuevo tipo de costumbres que les desincentivase al consumo de embriagantes. La concisa respuesta gubernamental indicaba que «ya se tratan con Secretarías Gobernación y Educación, así como Gobierno asuntos a que se refiere en escrito del 11 actual». ${ }^{25}$ Por su parte, en Coahuila, la Liga Femenil Lucha Social escribió al presidente Manuel Ávila Camacho, en junio de 1944, rogando su apoyo para evitar la venta del alcohol en el poblado de El Coyote de Matamoros. Sus integrantes argumentaban que el ejido era un lugar de trabajo y esta adicción suponía un «desplumadero y la ruina para nuestras familias», propiciaba «desorden y perdición para nuestros hijos», y «suscita casos de sangre», por lo que instaban al gobierno a que aplicase medidas para propiciar la «tranquilidad y progreso de los habitantes de este poblado». ${ }^{26}$

24 Correspondencia entre la Liga Femenil de Lucha Social de Santa Irente, La Gloria, Matamoros, Tamaulipas, y Secretaría de Presidencia en México, D. F., abril-junio de 1939, AGN, LC, leg. 1114, exp. 609/981.

25 Correspondencia entre la Liga Femenil del Zopilotita, Culiacán (Sinaloa) y el Departamento del Distrito Federal, México D. F., enero de 1940, AGN, LC, leg. 157, exp. 151.3/1411. Además, las mujeres denunciaban que había «individuos réprobos que con la ambición de adquirir un peso más, unden $[s i c]$ en la miseria a idiotas a un pueblo». En el memorial explican cómo el mismo alcalde era propietario, y su hermana regente, del principal expendio de la ciudad. Cuando la alcaldía era informada de que tendría lugar una inspección antialcohólica, cancelaban el suministro de bebidas durante varios días para burlar así los controles de salubridad.

26 Correspondencia entre la Liga Femenil de Lucha Social «Lázaro Cárdenas», Coyote, Municipio Matamoros, Coahuila, y el Departamento del Distrito Federal, México D. F., junio de 1944 a abril de 1945, AGN, MAC, 854, exp. 553/122. En su memorial, la liga recordaba al gobierno que tanto el comisariado ejidal como ellas mismas habían escrito en ocasiones anteriores a su oficina sin haber obtenido aún respuesta. 
Junto a la productividad y el equilibrio familiar, parte de la sociedad entendió también el alcoholismo como amenaza hacia la formación moral durante la infancia. Por ello, desde los años treinta, fueron frecuentes las quejas al respecto enviadas por las familias al despacho presidencial. Al fin y al cabo, numerosos cabarets, cantinas y pulquerías de la capital incumplían el reglamento que establecía la necesidad de distanciarlos de escuelas y centros de trabajo. ${ }^{27}$ En este sentido, las feministas, ya desde el Primer Congreso Feminista Panamericano, denunciaron que «hubiera un número de escuelas mucho menor que de expendios de bebidas alcohólicas». En aquel momento, propusieron que se exigiese al gobierno prohibir «el establecimiento de nuevas destilerías, tinacales o fábricas de cerveza». Según su criterio, la precariedad del nivel de vida, el absentismo escolar y el trabajo infantil hacían que el alcoholismo constituyera una escapatoria fácil para los niños y niñas que abandonaban la escuela o se incorporaban tempranamente al mercado laboral. ${ }^{28}$ Las instancias gubernamentales y dispositivos de control social buscaron también concienciar sobre el vínculo entre alcoholismo, explotación laboral y honorabilidad de las mujeres. Las revistas Detectives o Magazine Policía, publicadas en los años treinta y cuarenta, advertían de que la

\begin{abstract}
presencia de mujeres en cabarets y salones de baile era una vertiente más de la prostitución, con varios agravantes: no estaban sujetas a revisiones de [Departamento de] Salubridad - a diferencia de las prostitutas registradas-, por lo que eran una fuente de contagio de enfermedades venéreas y promovían el vicio del alcohol entre los clientes, además de que ellas mismas se aficionaban a las bebidas embriagantes. ${ }^{29}$
\end{abstract}

Este tipo de argumentos reforzaban la separación de espacios masculinos y femeninos. El cabaret o la taberna solo podían ser frecuentados por cualquier tipo de hombre, pero solo por mujeres que no se circunscribían a los códigos normativos vigentes de dignidad y honorabilidad. De forma subyacente, se asumía que la mujer distinguida estaba expuesta a infecciones morales y víricas que luego podía llegar a propagar en su entorno familiar. Es decir, se ligaba perversión y enfermedades sexuales. Los discursos estatales no denotaban preocupación por erradicar la prostitución en sí, por eliminar el régimen de explotación en el que vivían quienes la ejercían, o por luchar para que otras mujeres vulnerables no cayeran presas de la trata. Más Bien, se buscaba perpetuar los dos pilares del sistema patriarcal:

27 Rojas Sosa, 2019, 254-255.

28 Tuñón, 2011.

29 Rojas Sosa, 2019, 150-151. 
mujeres comerciables o consumibles (prostitutas), y mujeres negociables y aptas para casar (hijas, madres, esposas...). Es decir, recluir a las consideradas dignas en el régimen profiláctico del matrimonio y mantener sanas a las prostitutas registradas para que pudieran seguir siendo accesibles sin peligro para la clientela. A medio camino entre ambas, las camareras fueron estigmatizaba como seres maleables, tendentes a la embriaguez y al embaucamiento. Sin embargo, los diversos discursos oficiales no parecieron denunciar ni actuar contra las relaciones mercantiles y de poder machistas que posibilitaban la objetivación de prostitutas o camareras.

Por su parte, las ligas denunciaron que los expendios de bebidas alcohólicas, y el consumo de las mismas, no solo amenazaban la estabilidad familiar o aumentaba las tasas de criminalidad. Las tabernas y cantinas, señalaron, constituían el lugar de trabajo de camareras cuyos contratos solían ser temporales e inestables, mal remunerados y sin ningún tipo de cobertura sindical. Además, dado que solían estar casi exclusivamente frecuentadas por hombres, las ligas manifestaron, como los organismos y dispositivos de seguridad, que solían constituir espacios propicios para encubrir prácticas abusivas cercanas a la prostitución. En este aspecto, ya en el Congreso Nacional Femenino mexicano, las feministas conservadoras, moderadas y radicales solicitaron mayor control gubernamental sobre el consumo de alcohol, especialmente entre los varones. Ligado a ello, las feministas consideraban que en las cantinas se estaba explotando a las camareras para dar «servicios de falso amor, que son ultraje para nuestro sexo», por lo que exigían «la supresión de las casas de asignación». En este sentido, también explicaban cómo las mujeres que llegaban exiliadas o por algún tipo de inmigración forzada solían ser especialmente vulnerables frente a la trata de esclavas y la explotación laboral. Por ello las asistentes al congreso pidieron a las ligas de mujeres situadas en ciudades fronterizas o portuarias, como Veracruz, que orientasen y protegiesen a las recién llegadas. ${ }^{30}$

La mayoría de las ligas, sin embargo, no se posicionaron claramente en contra de la existencia de prostíbulos o casas de asignación. Partiendo de un análisis de clase, la Liga Femenil Leona Vicario, de Sonora, solicitaba que se aumentasen las «contribuciones con el fin de que se clausuren algunos de ellos [dispendios de alcohol o cantinas] por ser un perjuicio a nuestras mujeres obreras y campesinas [...] se sirva ordenar estrictamente se cierre los sábados y domingos». Como alternativa de empleabilidad para

30 Cano, 1990, 302-323. Estrada Urroz, 2016, 201-225. 
las mujeres y estímulo para «combatir la vagancia femenil», se proponía instalar fábricas de sweaters y pequeños comercios. Sin embargo, también se pedía «designar el radio de Casas de Asignación en lugar retirado de la Ciudad, por el bien moral de la niñez». ${ }^{31}$ Ambas propuestas ahondaban en el binarismo de la feminidad entre mujeres dignas e indignas. Respecto a las primeras, abriendo industrias donde los conocimientos «propios» de las mujeres, como la costura, fueran puestos al servicio de la producción a pequeña escala. Para las segundas, consintiendo la prostitución, ya que, en lugar de erradicarla, buscaban apartarla de los lugares más transitados por la ciudadanía. Es decir, llevar al régimen de lo invisible aquello que podía seguir existiendo siempre que no fuera visualizado.

En definitiva, el diagnóstico que las ligas ofrecieron sobre el alcoholismo recogía parte de los postulados planteados por los aparatos del poder políticos, las élites intelectuales y los medios de comunicación. Solapaban así aspectos morales (abstención y temperancia), sociológicos y políticos (la estabilidad familiar como célula básica de organización ciudadana), e higienistas y sanitarios (salud ciudadana). Sin embargo, desde un marco referencial comprometido con la integridad física y los derechos laborales de las mujeres, las ligas también expusieron argumentos económicos (centros de trabajo), sociales (reducción de los problemas familiares, las tensiones entre los habitantes, las peleas de sangre e incluso el vicio en el que podían caer los infantes), y feministas (explotación de las trabajadoras y protección frente a la trata de mujeres), todos ellos muy ligados al concepto de «maternidad social» (protección de la infancia) que caracterizó al movimiento sufragista liberal mexicano de primera mitad del siglo XX.

Para las ligas, la lucha contra el alcoholismo como degradante de la supuesta moralidad femenina parecía fundamental. Ahora bien, como se ha explicado, no parecieron oponerse abiertamente a la prostitución sin adjetivos. Se posicionaron contra la captación de mujeres inmigrantes que los tratantes realizaban en los puertos del país y criticaron la explotación laboral de las camareras porque se las empujaba a ofrecer servicios sexuales que excedían sus contratos. Sin embargo, no denunciaron la prostitución como negocio fundamentado en la explotación sexual de las mujeres, aunque algunas lo definían como «ultraje para nuestro sexo». A la mayoría de ligas no les incomodaba la práctica, sino los espacios. No las mujeres como cuerpos, sino el acceso desregulado a las estimadas como honorables. No las que

31 Correspondencia entre la Liga Femenil de Cananea (Sonora) y la Secretaría de Presidencia en México D. F., agosto de 1939, AGN, LC, leg. 156, exp. 151.3/1256. 
ya ejercían, sino las que corrían peligro de hacerlo. El consumo de alcohol como degradante de los hábitos y los códigos morales normativos de las mujeres aparecía así como uno de los principales causantes de la prostitución. Para evitar esta posibilidad, lo mejor era evitar las tentaciones, ocultar el mal ejemplo, expulsar los referentes negativos de los espacios habitados. Por ello quizás las ligas toleraron las cantinas y las casas de asignación siempre que estuvieran reguladas y se situasen a las afueras de las ciudades.

\section{Higiene y salubridad urbana para el bienestar de la comunidad}

Los proyectos políticos liberales de la segunda mitad del siglo XIX ligaron el progreso nacional al crecimiento económico y las relaciones internacionales, pero también al bienestar y la cultura de la ciudadanía. Posteriormente, el programa revolucionario trató de hacer extensivo estas premisas a sectores históricamente descuidados como los trabajadores, el campesinado, la población indígena y las mujeres. Ahora bien, este proceso generó a su vez marginalizaciones, estereotipos y prejuicios hacia estos mismos grupos tanto en el corto como en el largo plazo. ${ }^{32}$

La inmigración a los principales centros urbanos provocó un crecimiento de las unidades habitacionales sin un diseño urbanístico controlado. El aumento de la densidad poblacional no se vio acompañado en un principio por la introducción de drenajes, acometidas, pavimentos o gestiones de residuos, lo que incrementó el riesgo de contagio en caso de focos infecciosos. Por ello, la salubridad se convirtió en asunto de importancia nacional desde época porfiriana y especialmente desde el periodo posrevolucionario. Los debates sobre la higiene urbana apuntaron hacia la necesidad de reformar, ampliar y airear plazas y jardines, pero también hospitales, cárceles, asilos y gimnasios. ${ }^{33} \mathrm{Al}$ fin y al cabo, según Valenzuela, «estos proyectos contribuirían en el establecimiento de las bases de transformación urbana que tuvieron lugar tanto en la capital como en las ciudades en el interior de la República mexicana, sustentadas en la utopía de la ciudad racional, higiénica y moderna». ${ }^{34}$

Las principales iniciativas fueron la legislación sanitaria y la asistencia pública provista por el Consejo Nacional de Salubridad y la Secretaría de Salubridad, en especial la prevención dispensada por medio de campañas de

32 Pedraza Ramos, 2019. Cárdenas García, 2020.

33 Agostoni y Speckman, 2001. Agostoni, 2016.

34 Valenzuela Aguilera, 2015. 
vacunación. ${ }^{35}$ Sin embargo, se asumió que mejorar los niveles de salubridad exigía acompañar las medidas institucionales con un cambio en los hábitos y costumbres sociales. Por ello —explican Gudiño y Aguilar-, tanto la Secretaría de Educación Pública, desde 1921, como la Secretaría de Salubridad y Asistencia, desde 1940, trataron de inculcar al campesinado una nueva cultura de la higiene por medio de misiones culturales y revistas divulgativas con el fin de integrarlos al proyecto posrevolucionario de modernización nacional, unas ideas que no estuvieron exentas de asunciones clasistas y racistas. ${ }^{36}$ Del mismo modo, el gremio médico definió a las mujeres, y en especial a las madres de familia, como aliadas naturales «de la empresa de los higienistas [...] ya que tenía la misión de la maternidad, así como la de educar a sus hijos» para «fortalecer a la nación y contar con verdaderos ciudadanos: sanos, aptos para el trabajo y libres de vicios y enfermedad». ${ }^{37}$ Ahora bien, además de las políticas sanitarias preventivas y paliativas, y de los programas educativos mencionados, continuaba siendo necesario reducir los focos de infección que aquejaban a los núcleos poblacionales menos urbanizados. En este sentido, el acceso al agua potable y la canalización de las aguas residuales siguieron constituyendo dos cuestiones fundamentales a tratar para reducir la expansión y el contagio de enfermedades bacteriológicas.

Desde una perspectiva de género, la introducción de cañerías en los núcleos urbanos contribuyó a reducir el tiempo dedicado por las mujeres para cumplir con las responsabilidades que se presumían de su exclusiva competencia. Al fin y al cabo, la mayoría se ocupaba en tareas u oficios relacionados con el agua. Lavanderas, limpiadoras, cocineras y nixtamalizadoras empleaban decenas de horas semanales en surtir de agua a sus hogares o en acudir a recogerla para cumplir los términos de sus contratos. Estas responsabilidades y condicionantes cotidianos también contribuyeron a delimitar el marco referencial y el lugar de enunciación desde el que las integrantes de las ligas femeninas locales interpelaron al gobierno, como se explicará más adelante. ${ }^{38}$

35 Agostoni, 2010, 67-91; 2015, 355-370.

36 Aguilar Rodríguez, 2008; 2019. Gudiño, 2016, 71-98.

37 Agostoni, 2002, 1-22.

38 Mac-Clure, 2017, 170-172. En esas páginas, el autor explica para el caso de Chile que «el agua era ante todo un asunto de mujeres, beneficiarias indirectas de una expansión del abastecimiento de agua potable. Eran ellas quienes frecuentaban las pilas públicas u otras fuentes de agua durante el día, quienes acarreaban el líquido hasta sus viviendas quienes procuraban que alcanzara para la bebida, la preparación de alimentos, la limpieza, el lavado de ropa propia o ajena en el caso de las lavanderas. [...] Velar por el buen uso del agua en la vivienda era responsabilidad también de unas pocas mujeres que disponían de cañerías de fierro conectadas a sus casas». 
La documentación utilizada en esta investigación no posibilita conocer si las integrantes de las ligas femeninas del FUPDM o del BNMR en las provincias fueron receptoras de esos panfletos médicos, participaron en misiones culturales o recibieron algún tipo de instrucción sobre su responsabilidad hacia la infancia como madres de familia. Lo cierto, sin embargo, es que sus militantes enunciaron algunas de estas preocupaciones y problemáticas en sus misivas al gobierno, sumando en ocasiones cuestiones también planteadas por el propio movimiento feminista.

En San Bartolo Tenayuca, al norte de Ciudad de México, el ayuntamiento exigió en 1937 que se emprendiesen urgentemente obras de drenaje dado que se estaban produciendo brotes periódicos de enfermedades «por no tener manera de expeler las aguas impuras y deshechos [sic] que se reúne en la comunidad», una solicitud a la que se adhirió la Liga Femenil Lucha Social de la población. ${ }^{39}$ Por su parte, la Liga Femenil «Petra Herrera» (Francisco y Madero, Tamaulipas), se dirigió por motivos similares al presidente Cárdenas. En su misiva, las integrantes le solicitaban «su intervención para que en alguna forma podamos obtener a la mayor brevedad posible la instalación del agua potable en el ejido» porque «nuestras condiciones económicas no nos han permitido hasta ahora instalarla [...] siendo esta una demanda de primera necesidad hemos resuelto pedir de usted su intervención». ${ }^{40}$

Relacionado con las canalizaciones para el abasto de agua potable y el mantenimiento de los ejidos, se manifestaron las ligas femeninas del norte del país durante los periodos de sequía. En mayo de 1939, la Liga Femenil de Lucha Social de Quechehueca (Sonora) explicaban a presidencia que tenían un

poso [sic] artesiano porque nuestro pueblo carse [sic] mucho de sed en estos meses entrantes que es mayo junio y parte de julio son los meses que tomamos el agua con mucha dificultad ya desde ahora en adelante empesamos acareser [sic] de sed por motivo de que queda encharcada y se aogan $[s i c]$ muchos animales dentro dela agua y después yega [sic] a grado de quedar seco por completo». [Además, aunque] «acarrean agua

39 Correspondencia entre la Liga Femenil de Lucha Social y Secretaría de Presidencia en México D. F., junio de 1937, AGN, LC, 150, exp. 151.3/758.

40 Correspondencia entre la Liga Femenil Tamaulipas «Petra Herrera» y Secretaría de Presidencia en México D. F., julio de 1940, AGN, LC, 1118, exp. 609/1292. En este caso, el despacho presidencial derivó la petición al Departamento de Salubridad y al Agrario, si bien solo al cabo de un mes respondería la Dirección Nacional de Aguas Potables comprometiéndose a «efectuar el estudio correspondiente». La carta tiene la fecha de 1 de julio de 1940, días antes de los comicios generales que darían la victoria a Manuel Ávila Camacho. 
en tanques [...] como el pueblo ya es grande no nos dan a todas y pasamos algunas familias los días sin poder comer ysin beber. ${ }^{41}$

A las carencias materiales y las condiciones de podredumbre resultado de la muerte de los animales, las mujeres destacaban las responsabilidades que ellas tenían que asumir dentro de su comunidad, «nosotas emos echo [sic] todo lo posible por tener el agua potable pero no emos [sic] podido conseguir Ynosotras desearía mos que usted nos diera el despaldo que necesitamos para sulusionar $[$ sic $]$ nuestras necesidades». ${ }^{42}$

De igual forma, la Liga Femenil de Navojoa (Sinaloa) solicitaba en su misiva de julio de 1939 que se procediera a introducir «el servicio telefónico», pero sobre todo la «dotación de agua potable para nuestro poblado» porque «nuestros sufrimientos son continuos y los sacrificios bastantes pesados los que asemos [sic] para el acarreo de agua para abastecer nuestros humildes hogares». Una de sus integrantes, Antonia Salazar, pedía además que se estableciera el «estado seco en las regiones del Yaqui y de El Mayo, y que se construyan unos lavaderos públicos en las barriadas pobres de Navojoal». Y aunque las mujeres contaban con el apoyo de otros ejidatarios, la Secretaría de Salubridad se negaba a hacer intervenciones en espera de que se aprobasen unos nuevos estatutos que regulasen las obras de fomento. ${ }^{43}$

En la costa opuesta, las integrantes de la Liga Femenil de Lucha Social de Santa Irene (Matamoros, Tamaulipas) interpelaban al presidente Cárdenas no en beneficio propio, sino buscando la productividad del ejido y el bienestar de sus habitantes. En su misiva de abril de 1939 solicitaban «su valiosa cooperación económica para proveer de agua potable a nuestro poblado por ser esta una de las primeras necesidades que tenemos y que será la vida de nuestro propio Ejido. Pues ya hace tiempo que nuestra situación es penosísima por falta de este valioso elemento». Cabe subrayar que, como esta, la mayoría de ligas de mujeres en los Estados vinculaban sus ruegos petitorios a cuestiones implícitamente feministas no siempre, ni mayoritariamente, concernientes al sufragio. De ahí que el lema de la organización,

41 Correspondencia entre la Liga Femenil de Quechehueca, Sonora, y Secretaría de Presidencia en México D. F., mayo de 1939, AGN, LC, 136, exp. 136.3/2267. Mujeres de la Liga Femenil de Lucha Social escriben con múltiples faltas de ortografía («aogarse», «allude», «cooperativa», «sosial»), lo cual también es indicativo de la clase social y de las posibilidades que habían tenido de acceder al sistema educativo.

42 Idem.

43 Correspondencia entre la Liga Femenil de Navojoa, Sonora, y la Secretaría de Presidencia en México D. F., julio de 1939, AGN, LC, 1115, exp. 609/1034. 
y con el cual cerraban su mensaje, rezaba «por la liberación de la mujer campesina». ${ }^{44}$

En Veracruz, la Liga Femenil de Pueblo Viejo había conseguido consensuar un programa cuyas peticiones habían «merecido la aprobación de todos los comisariados y ligas femeniles». El pliego contemplaba la construcción de un local para sesionar, un botiquín para primeros auxilios, una escuela nocturna, una casa de maternidad, el desarrollo de pequeñas industrias para hombres y mujeres, y la introducción de agua potable para el pueblo. Al pie, Francisca Rangel y Liboria de León firmaban con el lema «El despertar de la mujer campesina». Este petitorio fue trasladado primero, no a instancias estatales o federales, sino a la secretaría de la Liga de Comunidades Agrarias y Sindicatos Campesinos, a la cual estaban subordinadas. El dirigente de la Liga masculina apoyaba explícitamente el documento firmado por las mujeres insistiendo en que «sean obsequiadas en sus deseos ya que lo que solicitan vendrá a ser de beneficio colectivo y adelanto para el poblado mencionado». La gobernación del Estado y la presidencia de la Federación apoyaron favorablemente la solicitud argumentando que «estos adelantos sociales que serán de beneficio de todos los campesinos de la Región». ${ }^{45}$ Estos dos últimos casos de Veracruz y Tamaulipas prueban la adhesión de las ligas por medio de sus lemas a los principios feministas consignados por el FUPDM, pero también permite constatar cómo sus preocupaciones materiales excedían la mera lucha por los derechos políticos de las mujeres.

Por su parte, las integrantes de la Liga Femenil Carrillo Puerto, Michoacán, interpelaban a Cárdenas recordando y agradeciendo la labor que había desempeñado en el Estados, las cuales fueron «para nosotros la salvación de la tiranía burguesa que imperaba contra nuestra histórica lucha social». En esta ocasión le solicitaban ayuda para terminar de desarrollar el plantel educativo y la electrificación del pueblo, pero especialmente para introducir «agua potable por ser pésimo el servicio actual» y para dotarles de un «molino de nixtamal para con esto hacer más livianas nuestras tareas diarias y así ayudar a nuestros esposos en sus labores». ${ }^{46}$

44 Correspondencia entre la Liga Femenil de Santa Irene, Tamaulipas, y la Secretaría de Presidencia en México D. F., mayo de 1939, AGN, LC, 1114, exp. 609/981.

45 Correspondencia entre la Liga Femenil de Pueblo Viejo, Jalapa, Veracruz, y Secretaría de Presidencia en México D. F., julio de 1938, AGN, LC, 153, exp. 151.3/1038.

46 Correspondencia entre la Liga Femenil de Colonia «Carrillo Puerto», Michoacán, y Secretaría de Presidencia en México D. F., octubre de 1939, AGN, LC, 157, exp. 151.3/1335. Hay que destacar que sus integrantes interpelaban al presidente desde la identidad conjunta con «nuestras hermanas de Raza en varias regiones de la República», pero también como «nosotras, indígenas del Pueblo de 'San Agustín del Pulque». 
Como se explicaba previamente, la solicitud realizada por las ligas femeninas relativas a las canalizaciones perseguía dos propósitos: mejorar las condiciones de salubridad y productividad agrícola de su comunidad, pero también reducir el tiempo dedicado a las tareas domésticas. Al fin y al cabo, el feminismo históricamente también ha sido una lucha por el tiempo personal del que se estaba privando a las mujeres, un tiempo que debían ocupar en atender responsabilidades y mandatos de género artificiales; en este caso, la provisión de agua para las letrinas o para la cocción y molienda del maíz con el que elaborar tortillas, elemento esencial en la dieta básica de las familias mexicanas. Sin embargo, paradójicamente, estas ligas impulsaban «el despertar de la mujer» liberando tiempo de «sus» responsabilidades cotidianas para dedicarlo, no tanto al ocio o a su formación, sino a apoyar a sus maridos en la labranza o el pequeño comercio.

\section{Conclusiones}

«Ninguno de nosotros — sostiene Judith Butler-, actuamos sin que se den las condiciones para nuestra actuación, aunque a veces tengamos que actuar para instaurar y preservar esas mismas condiciones» ${ }^{47} \mathrm{La}$ revolución y la constitución mexicana abrieron la puerta a la conformación de federaciones de masas en el marco de un Estado con carácter corporativo, y sentaron las bases para la extensión de derechos y libertades a toda la ciudadanía. Sin embargo, la existencia de estas condiciones de posibilidad no garantizaba su implementación, unas constricciones especialmente notables en el caso de las mujeres. Para poder exigir su acceso a la educación, el empleo remunerado y la política, estas desarrollaron plataformas cívicas de representación y actuación similares al sindicalismo. Por ello, en el tiempo de la posrevolución y la política de masas, decidieron organizarse, y a veces fueron organizadas, en distintos tipos de asambleas bajo el marco del FUPDM y el BNMR.

Las ligas femeninas adheridas a ambas entidades constituyen interesantes objetos de estudio para entender cómo las mujeres de distintos Estados se imbricaron simultáneamente en los proyectos revolucionario y feminista, pero también cómo interrogaron sus prácticas y fundamentos teóricos. En un momento en el que el sufragio aún no había sido aprobado,

47 Butler, 2017, 23. 
las ligas abrieron espacios para que las mujeres dialogasen, visibilizasen y politizasen desde lo local sus demandas socio-económicas ante las autoridades competentes. Además, estas ligas operaron también como entidades jurídicas desde las que denunciar la precariedad y vulnerabilidad de sus familias y conciudadanos concernientes a dos pilares claves en el debate sobre la modernización de México: alcoholismo e higienismo.

En este sentido, cabe recordar que las ligas surgieron cuando el Estado posrevolucionario buscaba institucionalizar una determinada concepción del progreso en todo el país por medio de las secretarías de educación, salubridad y obras públicas. Por entonces, el propio FUPDM aspiraba a consolidarse en todos los Estados para apoyar a las mujeres, especialmente a las más desfavorecidas, en la lucha por sus propios derechos políticos. Ahora bien, debe considerarse que la expansión del Estado corporativo por medio de la FUPDM y el BNMR hasta las localidades más pequeñas, y la integración de las mujeres en sus filas, quizás no habría sido posible sin la prexistencia de un tejido social que sustentase su expansión. Es decir, estas federaciones tal vez no se habrían consolidado en ejidos y municipalidades sin los círculos de campesinas y trabajadoras domésticas ya conscientes de las carencias materiales que aquejaban a su entorno en el momento que surgió la posibilidad de conformarse como plataforma cívica.

Llama la atención que la mayoría de pliegos petitorios enviados por estas ligas al despacho presidencial provienen de Estados donde el proceso revolucionario (1910-1917) tuvo especial impacto (Sonora, Sinaloa, Coahuila, Michoacán, Veracruz) y donde el PNR y PRM tuvieron una presencia y un control notable, debido sobre todo a la estirpe de presidentes sonorenses y michoacanos que articularon la institucionalización de la revolución en un partido de gobierno centralizador. Por otro lado, cabe además destacar las diferencias existentes entre las problemáticas abordadas por las mujeres mexicanas según los modelos productivos y características climáticas de sus regiones. Si las propuestas respecto al alcoholismo resultan similares en todo el país, en lo relativo a la salubridad y el higienismo las ligas norteñas muestran mayor preocupación por la provisión de agua potable debido a las acusadas sequías que afectaban a sus poblaciones.

Las integrantes de las ligas mostraron así la capacidad de agencia suficiente para tejer solidaridades y exigir demandas fundamentadas y fundamentales en sus experiencias cotidianas. Estas cuestiones redefinieron y enriquecieron desde lo local las sinergias generadas por la lucha sufragista impulsada en las capitales. Por ello, la conclusión que sugiere este artículo 
es que las ligas femeninas locales plantearon interrogantes tanto al feminismo sufragista como al proyecto revolucionario. Primero, porque dando preponderancia a la reducción del alcoholismo o la provisión de agua potable y servicios de salubridad en detrimento del sufragio, las ligas excedieron tanto el núcleo ideológico como los horizontes programáticos del FUPDM, el cual luchó por el voto hasta 1940, si bien las ligas parecieron estar más en sintonía con el feminismo no sufragista del BNMR a partir de esa misma fecha. Segundo, porque, aunque los memoriales de las ligas engranaban con las concepciones vigentes sobre el progreso y la modernidad promovidas por el Estados posrevolucionario, al mismo tiempo, las problematizaron desde una experiencia femenina y parcialmente feminista. Este posicionamiento no rompía con el binarismo mujeres honorables/mujeres indignas, con la división genérica del trabajo, o con el concepto de maternidad social. Sin embargo, se mostró efectivo a la hora de imaginar nuevas vías para la liberación de las mujeres en función de las posibilidades que ofrecían los contextos locales y las condiciones materiales desde los cuales interpelaban al gobierno.

En definitiva, las ligas se constituyeron en «cuerpos-políticos» que posibilitaron a las mujeres visibilizar y politizar sus propios diagnósticos de la cultura higiénica, el fomento urbano y la justicia social, pero también de la emancipación femenina. Cuando aún las mujeres no tenían voz ni voto en las instituciones representativas del poder político, las ligas contribuyeron a pluralizar su rol en la esfera pública y a complejizar su implicación en las políticas de transformación social.

Recibido, 24 de agosto de 2020 Segunda versión, 24 de noviembre de 2020 Aprobado, 18 de diciembre de 2020

\section{Referencias bibliográficas}

Aguilar Rodríguez, Sandra, «Alimentando a la nación: género y nutrición en México (1940-1960)», Revista de Estudios Sociales, 29, Bogotá, 2008, 28-41.

Aguilar Rodríguez, Sandra, «Raza y alimentación en el México del siglo XX», Inter Disciplina, 7:19, Ciudad de México, 2019, 119-138.

Álvarez-Pimentel, Ricardo José, «Guerra Fría, Guerra Cristera, Guerreras Católicas: el conservadurismo y feminismo católico de la Juventud Católica Femenina Mexicana (JCFM), 1926-1939», Nuevo Mundo Mundos Nuevos, París, 
en línea, 02/10/2017. Disponible en: http://journals.openedition.org/nuevomundo/71299 [Consultado: 20/11/2020].

Agostoni, Claudia y Speckman, Elisa (eds.), Modernidad, tradición y alteridad: la ciudad de México en el cambio de siglo (XIX y XX), Ciudad de México, Universidad Nacional Autónoma de México, 2001.

Agostoni, Claudia, «Discurso médico, cultura higiénica y la mujer en la ciudad de México al cambio de siglo (XIX-XX)», 18:1, Mexican Studies/Estudios Mexicanos, Riverside, 2002, 1-22.

Agostoni, Claudia, «Médicos Rurales y Brigadas de Vacunación en la Lucha Contra la Viruela en el México Posrevolucionario, 1920-1940», Canadian Journal of Latin American and Caribbean Studies / Revue canadienne des études latino-américaines et caraïbes, 35:69, Toronto, 2010, 67-91.

Agostoni, Claudia, «Control, contención y educación higiénica en las campañas de vacunación contra la viruela en México durante la década de 1940», História, Ciências, Saúde-Manguinhos, 22:2, Río de Janeiro, 2015, 355-370.

Agostoni, Claudia, Curar, sanar y educar: enfermedad y sociedad en México: siglos XIX y XX, México, Universidad Nacional Autónoma de México, 2016.

Anaya Merchant, Luis, «La construcción de la memoria y la revisión de la revolución», Historia Mexicana, 44:4, Ciudad de México, 1995, 525-536.

Basurto, Armando, «En busca de la herencia política de la Revolución mexicana. Una propuesta analítica», Revista Mexicana de Ciencias Políticas y Sociales, 64:235, Ciudad de México, 2019, 23-48.

Butler, Judith, Cuerpos aliados y lucha política. Hacia una teoría performativa de la asamblea, Bogotá, Planeta, 2017.

Cano, Gabriela, «México 1923: Primer Congreso Feminista Panamericano», Debate Feminista, 1, Ciudad de México, 1990, 302-323.

Cano, Gabriela, «Adelina Zendejas: arquitecta de su memoria», Debate Feminista, 8, Ciudad de México, 1993, 387-400.

Cano, Gabriela; Vaughan, Mary Kay y Olcott, Jocelyn (comps.), Género, poder y política en el México posrevolucionario, Ciudad de México, Fondo de Cultura Económica, 2009.

Cárdenas García, Nicolás, «Nacionalismo, revolución y racismo en México. La expulsión de los chinos (1910-1934), Ayer. Revista de Historia contemporánea, 117:1, Madrid, 2020, 221-248.

Cueva Tazzer, María Lourdes «Textos y prácticas de mujeres comunistas en México, 1919-1934», tesis doctoral dirigida por Ana Lau Jaiven, Ciudad de México, Universidad Autónoma Metropolitana, 2009. Disponible en http:// 148.206.53.233/tesiuami/UAMI14770.pdf [Consultado: 12/02/2020].

De Dios Vallejo, Delia Selene, «La participación de las mujeres en la democracia», en Galeana, Patricia (ed.), La revolución de las mujeres en México, Ciudad de México, Instituto Nacional de Estudios Históricos de las Revoluciones de México, 2014, 117-119. 
De Haan, Francisca, «Continuing Cold War paradigms in western historiography of transnational women's organisations: The case of the Women's International Democratic Federation (WIDF)», Women's History Review, 19:4, Portsmouth, 2010, 547-573.

De La Torre Torres, Rosa María; Vázquez, Olalde y Yesenia, Brenda, «El papel de las mujeres en el constituyente de 1916 y la apertura de la participación política», en Soberanos Fernández, José Luis y López Sánchez, Eduardo Alejandro (coords.), 1916 rumbo a la Constitución de 1917, Ciudad de México, Instituto de Investigaciones Jurídicas, Universidad Nacional Autónoma de México, 2018, 131-146.

Espinosa Meléndez, Pedro, «Antifeminismo y feminismo católico en México. La Unión Femenina Católica mexicana y la revista Acción Femenina, 19331958», Revista Interdisciplinaria de estudios de Género de El Colegio de México, 6, Ciudad de México, 2019, 1-34.

Estrada Urroz, Rosalina, «La trata de blancas y su diferente atención: Buenos Aires y Veracruz, puertos de tráfico de mujeres francesas en las primeras décadas del siglo XX», en Speckman Guerra, Elisa y Bailón Vásquez, Fabiola (coords.), Vicio, prostitución y delito. Mujeres transgresoras en los siglos XIX y XX, México, Instituto de Investigaciones Históricas, Universidad Nacional Autónoma de México, 2016, 201-225.

Estudillo García, Joel; Jaiven, Ana Lau y Nieto Arizmendi, José Edgar (coords.), Diccionario enciclopédico del feminismo y los estudios de género en México, Ciudad de México, Centro Interdisciplinar de Estudios de Género, Universidad Nacional Autónoma de México, 2019, 224-225.

Fernández Aceves, María Teresa, Mujeres en el cambio social en el siglo XX mexicano, Ciudad de México, Siglo XXI, 2014.

Fowler-Salamini, Heather y Vaughan, Mary Kay (ed.), Mujeres del campo mexicano, 1850-1990, México, El Colegio de Michoacán/Benemérita Universidad Autónoma de Puebla, 2003.

Gradskova, Yulia, «Women's international Democratic Federation, the "Third World", and the Global Cold War from the late-1950s to the mid-1960s», Women's History Review, 29:2, Portsmouth, 2020, 270-288.

Gudiño, María Rosa, «Educación higiénica y consejos de salud para campesinos en el Sembrador y el Maestro rural, 1929-1934», en Agostoni, Claudia (coord.), Curar, sanar y educar: enfermedad y sociedad en México: siglos XIX y XX, Ciudad de México, Universidad Nacional Autónoma de México, 2016, 71-98.

Hernández Carballido, Elvira, «Periódicos pioneros fundados por mujeres: Las hijas del Anáhuac, El álbum de la mujer, El correo de las señoras, y Violetas del Anáhuac. (1873-1889)», Derecho a comunicar, 6, Ciudad de México, 2012, 64-81.

Hershfield, Joanne, Imagining La Chica Moderna. Women, Nation, and Visual Culture in Mexico, 1917-1936, Durham/Londres, Duke University Press, 2008. 
Knight, Alan, «La revolución mexicana: ¿burguesa, nacionalista, o simplemente "gran rebelión"»?, Cuadernos políticos, 48, Ciudad de México, 1986, 5-32.

Lau Jaiven, Ana y Rodríguez Bravo, Roxana, «El sufragio femenino y la Constitución de 1917. Una revisión», Política y cultura, 48, Ciudad de México, 2017, 57-81.

Mac-Clure, Óscar, Los orígenes de las políticas sociales en Chile, Santiago de Chile, Ediciones Universidad Alberto Hurtado, 2017.

Mitchell, Stephanie, «Por la liberación de la mujer: Women and the Anti-Alcohol Campaign», en Mitchell, Stephanie y Schell, Patience A. (eds.), The women's revolution in Mexico, 1910-1953, Plymouth, Rowman \& Littlefield Publishers, 2007, 165-187.

Oikión Solano, Verónica, «Mujeres comunistas en México. Desigualdad social y lucha política, 1935-1955», en Valobra, Adriana y Yusta, Mercedes (eds.), Queridas camaradas. Historias iberoamericanas de mujeres comunistas, Buenos Aires, Miño y Dávila, 2017.

Oikión Solano, Verónica, Cuca García (1889-1973), por las causas de las mujeres y la revolución, Zamora, El Colegio de Michoacán/Centro de Investigaciones y Estudios de Género de la Universidad Nacional Autónoma de México/El Colegio de San Luis, 2018.

Olcott, Jocelyn, Revolutionary women in Postrevolutionary Mexico, Durham, Duke University Press, 2007.

Olcott, Jocelyn, «El centro no puede sostenerse. Las mujeres en el Frente Popular de México», en Cano, Gabriela; Vaughan, Mary Kay y Olcott, Jocelyn (comps.), Género, poder y política en el México posrevolucionario, Ciudad de México, Fondo de Cultura Económica, 2010, 307-375.

Orozco-García, Eva Nohemi, «Las Mujeres Sinarquistas (1937-1962): Las manos ocultas en la construcción del sentimiento nacionalista mexicano de derecha», tesis doctoral dirigida por Sandra McGee-Deutsch, El Paso, University of Texas at El Paso, 2019. Disponible en: https://scholarworks.utep.edu/cgi/ viewcontent.cgi?article $=1136 \&$ context=open_etd [Consultado: $25 / 05 / 2020$ ].

Paz Trueba, Yolanda de y Bracamonte, Lucía, «Mujeres que piden: estrategias diversas en un contexto de crisis. La provincia de Buenos Aires entre 1913 y 1920», Anuario de Estudios Americanos, 77:1, Sevilla, 2020, 25-53.

Pedraza Ramos, Alejandro Karin, «El indigenismo en México como racismo de Estado: mestizaje asimilacionista y esterilización forzada», Itinerarios, 29, Varsovia, 2019, 215-236.

Peniche Rivero, Piedad, «Los congresos feministas de 1916, el obsequio legal y la denegación del sufragio a las congresistas por el general Alvarado», en Instituto Nacional de Estudios Históricos de las Revoluciones de México, Mujeres y Constitución: de Hermila Galindo a Griselda Álvarez, Ciudad de México, Instituto Nacional de Estudios Históricos de las Revoluciones de México, 2017, 23-48. 
Portugal Speedle, Ana María, «Esther Chapa Tijerina, 22 años buscando el voto», en Lovera López, Sara (coord.), Las indispensables. Recuperando la memoria, Ciudad de México, Instituto Nacional de las Mujeres, 2018, 237-249.

Rojas Sosa, Odette María, La metrópoli viciosa. Alcohol, crimen y bajos fondos, Ciudad de México, Universidad Nacional Autónoma de México, 2019.

Santillán, Martha, «Tradicionalist Discourse on Motherhood: Excélsior and Prolific Mothers during Ávila Camacho’s Administration», Secuencia, 77, Ciudad de México, 2010, 91-110.

Serrano Guerra, Luis Antonio; Sánchez Morelos, María Luisa; Martínez Fernández, Patricia; Valdez, Sara y De la Mora, María Teresa, «La cosmovisión del trabajador social como parte de la institucionalidad», Vínculos. Sociología, análisis y opinión, 3, Guadalajara, 2015, 13-32.

Tuñón Pablos, Enriqueta, «Tres momentos claves del movimiento sufragista en México (1917-1953)», en Galeana, Patricia (ed.), La revolución de las mujeres en México, Ciudad de México, Instituto Nacional de Estudios Históricos de las Revoluciones de México, 2016, 81-99.

Tuñón Pablos, Esperanza, Mujeres que se organizan. El Frente Único Pro Derechos de la Mujer 1935-1938, Ciudad de México, Universidad Nacional Autónoma de México, 1992.

Tuñón Pablos, Esperanza y Martínez Ortega, Juan Iván, «La propuesta políticofeminista de Hermila Galindo. Tensiones, oposiciones y estrategias», Revista interdisciplinaria de estudios de género de El Colegio de México, 3:6, Ciudad de México, 2017, 1-35.

Tuñón, Julia, Voces a las mujeres. Antología del pensamiento feminista mexicano, Ciudad de México, Universidad Autónoma de la Ciudad de México, 2011.

Urias Horcasitas, Beatriz, Historias secretas del racismo en México (1920-1950), Barcelona, Tusquets, 2007.

Valenzuela Aguilera, Alfonso, «El bosque en la ciudad: la invención del urbanismo moderno en la Ciudad de México (1870-1930)», Amérique Latine Histoire et Mémoire. Les Cahiers ALHIM, 29, París, en línea, 18/06/2015. Disponible en: http://journals.openedition.org/alhim/5237 [Consultado: 10/02/2020].

Vaca, Agustín, Los silencios de la historia: las cristeras, Zapoapan, El Colegio de Jalisco, 1998.

Vargas Reynoso, Luis Ángel, «Higiene y salud, derechos constitucionales: las enfermedades en la Revolución como problema social (1915-1918)», en Soberanos Fernández, José Luis y López Sánchez, Eduardo Alejandro (coords.), 1916 rumbo a la Constitución de 1917, Ciudad de México, Instituto de Investigaciones Jurídicas, Universidad Autónoma de la Ciudad de México, 2018, 189-207.

Zapata Schaffeld, Francisco, «¿Democratización o rearticulación del corporativismo? El caso de México», Política. Revista de Ciencia Política, 42, Santiago de Chile, 2004, 13-40. 